\title{
Variación genética de cuatro especies de árboles tropicales de la Reserva de la Biosfera Selva El Ocote, Chiapas, México
}

\section{Genetic variation of four tropical tree species in the Selva El Ocote Biosphere Reserve, Chiapas, Mexico}

\section{Acta Botanica Mexicana}

\author{
Lorena Ruiz-Montoya1’3 (iD, María Zenaida López-López' (iD), Consuelo Lorenzo' (iD, Maricela García-Bautista² (iD, Neptalí \\ Ramírez-Marcial' (iD
}

\section{Resumen:}

Antecedentes y Objetivos: La variación genética de especies de árboles es escasamente conocida para los bosques tropicales de México. El objetivo fue analizar la diversidad genética de Brosimum alicastrum (Moraceae) y Sapium macrocarpum (Euphorbiaceae) (especies sucesionalmente intermedias y con dispersión zoocora) y de Cecropia peltata (Cecropiaceae) y Heliocarpus appendiculatus (Malvaceae) (sucesionalmente tempranas o pioneras, con síndrome de dispersión zoocora y anemócora, respectivamente), en la selva mediana subperennifolia de la Reserva de la Biosfera Selva El Ocote (REBISO), Chiapas, México.

Métodos: Se amplificaron dos regiones de ADN del gen nuclear ribosomal, ITS 1-2 e ITS 3-4, como marcadores genéticos. El ADN se extrajo de hojas o cambium de árboles de las especies elegidas en tres localidades (subpoblaciones) de la REBISO. A partir de secuencias concatenadas (578 pb), se obtuvieron los estimadores de diversidad y diferenciación genética.

Resultados clave: Se registraron ocho haplotipos en B. alicastrum, 12 en S. macrocarpum, cinco en H. appendiculatus y seis en C. peltata. Los valores más altos para la mayoría de los estimadores se presentaron en $S$. macrocarpum $(\pi=0.0047, H d=0.79, s=10)$, y también registró la menor diferenciación entre localidades $\left(\Phi_{\mathrm{st}}=0.22\right)$. Heliocarpus appendiculatus y $C$. peltata presentaron, valores más bajos de diversidad, pero una mayor diferenciación entre las localidades (Фst $\sim 0.80$ ).

Conclusiones: En general, el mayor nivel de diversidad genética se registró en S. macrocarpum, especie sucesionalmente intermedia y con síndrome de dispersión zoocora. Se observó una menor variación y mayor diferenciación en las especies pioneras, $H$. appendiculatus y $C$. peltata. La variación genética observada se ajusta a un modelo evolutivo neutral, por lo que probablemente el patrón de variación observado se debe a procesos evolutivos aleatorios. No obstante, el síndrome de dispersión y su afinidad sucesional influyen en la distribución espacial de la diversidad genética.

Palabras clave: áreas naturales protegidas, bosque tropical, genética de la conservación, ITS, selva mediana subperennifolia.

\begin{abstract}
:
Background and Aims: Genetic variation of tree species is poorly understood for tropical forests of Mexico. The objective was to analyze the genetic diversity of Brosimum alicastrum (Moraceae) and Sapium macrocarpum (Euphorbiaceae), successionally intermediate species and dispersed by animal (zoochory), and Cecropia peltata (Cecropiaceae) and Heliocarpus appendiculatus (Malvaceae), early successional or pioneer, zoochory and anemochory dispersal syndrome, respectively, of the semi-evergreen forest of the Selva El Ocote Biosphere Reserve (REBISO), Chiapas, Mexico.

Methods: Two DNA regions of the ribosomal nuclear gene, ITS 1-2 and ITS 3-4, were amplified as genetic markers. DNA was extracted from leaves or cambium of trees of the chosen species from three locations (or subpopulations) in the REBISO. From concatenated sequences ( 578 bp), the estimators of genetic diversity were obtained.

Key results: Eight haplotypes were recorded in B. alicastrum, 12 in S. macrocarpum, five in H. appendiculatus and six in C. peltata. The highest values for most of the diversity estimators were observed in $S$. macrocarpum $(\pi=0.047, H d=0.79, s=10)$, and the lowest differentiation between subpopulations was also recorded in this species $\left(\Phi_{\text {st }}=0.22\right)$. In contrast, $H$. appendiculatus and $C$. peltata presented lower values but greater differentiation between the subpopulations (Фst 0.80).

Conclusions: Overall, the highest level of genetic diversity was recorded for $S$. macrocarpum, a successionally intermediate species and with zoochorous dispersal syndrome. Less variation was observed within species and greater differentiation in successionally pioneer species, $H$. appendiculatus and $C$. peltata. The genetic variation observed fits well a neutral evolutionary model; therefore, the pattern of genetic variation probably was driven by random evolutionary processes. However, the dispersal syndrome and successional affinity influence spatial distribution of genetic diversity.
\end{abstract}

Key words: conservation genetics, ITS, natural protected area, semi-evergreen forest, tropical forest.

${ }^{1}$ El Colegio de la Frontera Sur, Departamento de Con- Recibido: 27 de enero de 2021. servación de la Biodiversidad, Carretera Panamericana Revisado: 22 de marzo de 2021.

y Periférico Sur s/n, Barrio de María Auxiliadora, 29290 Aceptado por Marie-Stéphanie Samain: 21 de mayo de San Cristóbal de las Casas, Chiapas, México.

${ }^{2}$ El Colegio de la Frontera Sur, Laboratorio de Genética, Carretera Panamericana y Periférico Sur s/n, Barrio de María Auxiliadora, 29290 San Cristóbal de las Casas, Chiapas, México.

${ }^{3}$ Autor para la correspondencia: Iruiz@ecosur.mx 2021.

Publicado Primero en línea: 09 de junio de 2021

Publicado: Acta Botanica Mexicana 128 (2021).
Citar como: Ruiz-Montoya, L., M. Z. López-López, C. Lorenzo, M. García-Bautista y N. Ramírez-Marcial. 2021. Variación genética de cuatro especies de árboles tropicales de la Reserva de la Biosfera Selva El Ocote, Chiapas, México. Acta Botanica Mexicana 128: e1847. DOI: https://doi.org/10.21829/abm128.2021.1847 


\section{Introducción}

Los bosques tropicales tienen al menos tres funciones globales fundamentales: 1) la capacidad de almacenar carbono en forma de biomasa, 2) contener una alta diversidad biológica y 3) regular el clima y agua; dichas funciones los convierten en ecosistemas sumamente importantes como amortiguadores del cambio climático (FAO, 2014). Desafortunadamente la extensión de los bosques tropicales se reduce gradualmente, debido a la creciente necesidad de incrementar los sistemas agropecuarios para la producción alimentaria (Ricker et al., 2007). Uno de los pocos remanentes de bosque tropical subcaducifolio (Rzedowski, 2006) se encuentra en la Reserva de la Biosfera Selva El Ocote (REBISO), un área natural protegida en Chiapas (Flamenco-Sandoval et al., 2007). Ahí se conservan al menos 191 especies de árboles tropicales (Ramírez-Marcial et al., 2017), para las cuales hay pocos estudios sobre la diversidad genética que albergan (Cruz-Salazar et al., 2021).

Los estudios genéticos son necesarios y relevantes para la toma de decisiones con respecto a la conservación, tanto de las especies vegetales como de los procesos que operan dentro de las comunidades (Vellend, 2005). Por ejemplo, las poblaciones con bajos niveles de diversidad genética pueden ser más vulnerables al cambio climático, por lo que su permanencia puede verse comprometida (Hughes et al., 2008).

Específicamente en las especies de árboles la diversidad genética está determinada por sus características ecológicas e historias de vida, así como por los eventos geológicos del pasado que han definido su distribución geográfica y variación genética actual (Loveless y Hamrick, 1984; Chávez-Pesqueira y Núñez-Farfán, 2016; Gamba y Muchhala, 2020). Desde la perspectiva ecológica, sus mecanismos de dispersión de polen, frutos y semillas juegan un papel importante en su estructura y diversidad genética (Hamrick y Godt, 1996; Hamrick, 2004; Figueroa-Esquivel et al., 2010; Gamba y Muchhala, 2020), porque constituyen medios para el intercambio de alelos entre poblaciones. Además, se reconoce que la composición y abundancia de árboles es variable conforme avanza el desarrollo de un bosque, por lo que a lo largo de la sucesión ecológica las especies pueden estar sujetas a diferentes filtros ambientales (Guariguatta y Ostertag, 2002), que pueden influir en su composición genética en un tiempo dado (Vera-Maloof et al., 2019).

Generalmente, al inicio de la formación de un bosque las especies pioneras suelen ser muy abundantes, y llegan a ser escasas conforme avanza el proceso sucesional (Gómez-Pompa, 1971; Nathan y Muller-Landau, 2000; Martínez-Orea et al., 2009). Estas especies pioneras son las primeras que colonizan las áreas abiertas, se caracterizan por tener frutos generalmente secos, semillas pequeñas y numerosas, que son dispersadas principalmente por el viento, sus plántulas germinan bajo luz directa y presentan altas tasas de crecimiento (Turner, 2004). Las especies de árboles más comunes en etapas sucesionales intermedias se distinguen por tener tolerancia a la sombra, presentar un crecimiento lento, frutos carnosos y depender de la dispersión, principalmente por animales que se alimentan de ellas (Dalling, 2002).

Las poblaciones de especies de árboles con síndrome de dispersión por viento (anemocoria) o animales (zoocoria) y con sistema de fertilización cruzada, tienen mayor diversidad genética y menor diferenciación poblacional que aquellas con síndrome de dispersión barocora y con autofertilización (Hamrick et al., 1992; Nason, 2002). Recientemente, Gamba y Muchhala (2020) demostraron que la distribución latitudinal explica la mayor parte de la varianza de los valores de diferenciación genética $\left(F_{S T}\right)$ entre plantas, seguida del modo de polinización, sistema de apareamiento y forma de vida (árbol, arbusto). En su trabajo los valores de $F_{\text {ST }}$ fueron superiores para especies tropicales, polinizadas por pequeños insectos, con reproducción mixta y forma de vida no-leñosa.

El conocimiento de la diversidad y estructura genética de los árboles tropicales proporciona información potencialmente útil para el planteamiento de estrategias de manejo y conservación con perspectiva evolutiva (Frankham, 1995; Nason, 2002; Piñero et al., 2008). Una posible decisión de manejo puede ser que, si las especies presentan poblaciones genéticamente diferenciadas, serían necesarios esfuerzos de conservación para preservar todas las poblaciones. Por otro lado, si se llega a una limitación de recursos para conservación, entonces la recomendación sería enfocar los esfuerzos de conservación en la población con la mayor diversidad genética, porque sería con el ma- 
yor potencial evolutivo. Sin embargo, aún es insuficiente el conocimiento de la diversidad genética de las especies de árboles que componen el bosque tropical subcaducifolio en general, y en particular para la REBISO, por lo que se desarrolló el presente trabajo para ampliar dicho conocimiento. El estudio se realizó guiado por las siguientes preguntas: ¿Cuál es el nivel de diversidad genética de árboles tropicales en México? ¿El patrón de variación genética se asocia con características ecológicas como la afinidad sucesional y síndrome de dispersión? El objetivo particular fue analizar la diversidad genética de las especies sucesionalmente intermedias Brosimum alicastrum Sw. (Moraceae) y Sapium macrocarpum Müll. Arg. (Euphorbiaceae), con dispersión zoocora, y las sucesionalmente tempranas o pioneras, $\mathrm{Ce}$ cropia peltata L. (Cecropiaceae) y Heliocarpus appendiculatus Turcz. (Malvaceae), con síndrome de dispersión zoocora y anemócora, respectivamente, en la Reserva de la Biosfera Selva El Ocote (REBISO). Nuestras expectativas fueron encontrar los valores más altos de diversidad y diferenciación entre las subpoblaciones de las especies sucesionalmente pioneras y con síndrome de dispersión zoocora.

\section{Materiales y Métodos}

\section{Área de estudio}

La Reserva de la Biosfera Selva El Ocote (REBISO) fue designada área protegida desde 1997 y tiene una extensión de $101.3 \mathrm{~km}^{2}$. Se considera de especial importancia biológica y cultural debido a su proximidad a los bosques lluviosos de los Chimalapas en Oaxaca y Uxpanapa en Veracruz, que forman el corredor biológico Selva Zoque (SEMARNAT, 2001). Se localiza dentro de los municipios Cintalapa de Figueroa, Ocozocoautla de Espinosa, Tecpatán y Jiquipilas, en el estado de Chiapas, México, entre las coordenadas $16^{\circ} 45^{\prime} 42^{\prime \prime}$ y $17^{\circ} 09^{\prime} 00^{\prime \prime} \mathrm{N}$ y $93^{\circ} 21^{\prime} 20^{\prime \prime}$ y $93^{\circ} 47^{\prime \prime} 00^{\prime \prime O}$ (SEMARNAT, 2001). Los suelos son poco profundos, de origen calcáreo y el terreno es accidentado. El clima es cálido subhúmedo, cuya vegetación dominante es la selva mediana subperennifolia (SEMARNAT, 2001; Ramírez-Marcial et al., 2017).

Dentro de la zona de amortiguamiento del polígono de la REBISO se encuentran numerosos poblados, que para satisfacer sus necesidades básicas de alimentación y vivienda han deforestado diversas áreas y afectado la composición y estructura de la vegetación natural (Flamenco San- doval et al., 2007). De tal manera que es posible observar áreas con bosques en diferentes estados de conservación (SEMARNAT, 2001).

Para este estudio se eligieron los bosques conservados cercanos a tres localidades de la REBISO: Emilio Rabasa, Veinte Casas y Nuevo San Juan Chamula en el municipio de Ocozocuautla de Espinoza (Fig. 1), por el relativo fácil acceso al área más conservada de la reserva (SEMARNAT, 2001). La vegetación predominante en los sitios de muestreo corresponde al bosque tropical subcaducifolio (sensu Rzedowski, 2006), con mayor proporción de especies intermedias y tardías que pioneras (Ramírez-Marcial et al., 2017).

\section{Especies de estudio}

Se eligieron cuatro especies arbóreas, dos con afinidad sucesional temprana o pionera: Cecropia peltata (Cecropiaceae) y Heliocarpus appendiculatus (Malvaceae), y dos con afinidad sucesional intermedia: Brosimum alicastrum (Moraceae) y Sapium macrocarpum (Euphorbiaceae) (Cuadro 1).

El guarumbo, Cecropia peltata, es una especie pionera de zonas perturbadas por factores naturales o asociados a las actividades humanas; es visible debido a su copa extendida y grandes hojas y produce interrumpidamente abundantes frutos (aquenios agregados) que son consumidos y dispersados por numerosas especies de aves y mamíferos (Cornelis et al., 2005). Es utilizada para acelerar la regeneración de áreas tropicales perturbadas (Lobova et al., 2003), así como para la fabricación de tableros aglomerados y pulpa para elaborar papel (Pennington y Sarukhán, 2005). Es una especie que no está listada en la Norma Oficial Mexicana NOM-059-SEMARNAT-2010 (SEMARNAT, 2010).

El corcho, Heliocarpus appendiculatus, es pionero, dioico y es característico de la vegetación secundaria del bosque tropical subcaducifolio (Vibrans, 2009). Sus frutos son del tipo cápsula y sus semillas son dispersada principalmente por el viento (anemocoria) (Figueroa y Vázquez-Yanes, 2002). Tiene varios usos, entre ellos están el artesanal, medicinal, y también es materia prima para la elaboración de papel amate (Vibrans, 2009). En Costa Rica se ha propuesto la plantación monoespecífica del corcho, debido a la demanda internacional por su uso tradicional como fuente de mucílago en la clarificación de dulces (Quezada Moreno 


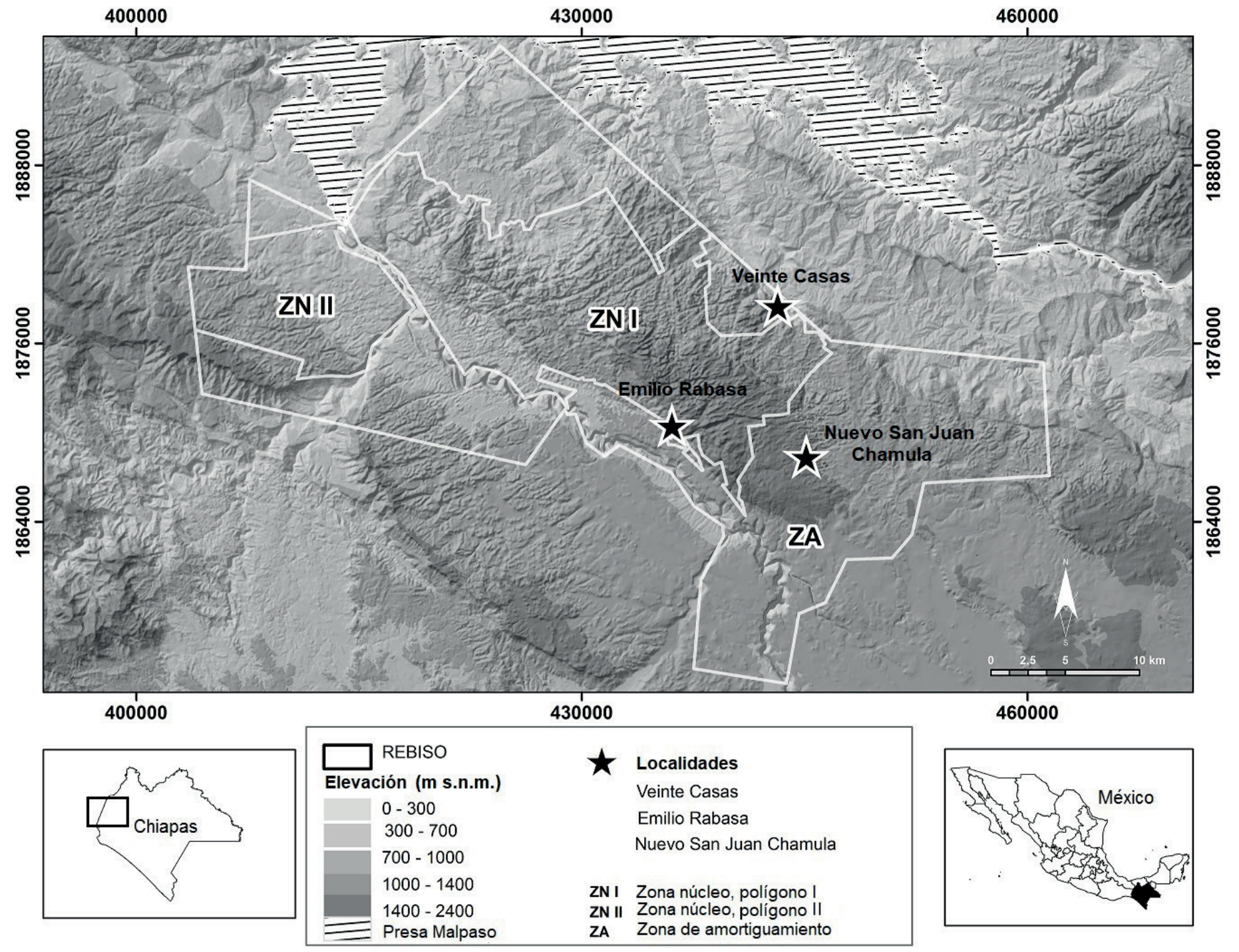

Figura 1: Ubicación geográfica de las localidades de muestreo de las especies de árboles Brosimum alicastrum Sw., Sapium macrocarpum Müll. Arg., Heliocarpus appendiculatus L. y Cecropia peltata Turcz., en la Reserva de la Biosfera Selva El Ocote (REBISO), Chiapas, México.

Cuadro 1: Características biológicas y ecológicas de cuatro especies arbóreas de la selva mediana subperennifolia de la Reserva de la Biosfera Selva El Ocote (REBISO), Chiapas, México.

\begin{tabular}{|c|c|c|c|c|c|}
\hline Especie & Familia & Fruto & $\begin{array}{l}\text { Síndrome de } \\
\text { dispersión }\end{array}$ & $\begin{array}{l}\text { Vector de } \\
\text { dispersión }\end{array}$ & $\begin{array}{l}\text { Afinidad } \\
\text { sucesional }\end{array}$ \\
\hline Brosimum alicastrum Sw. & Moraceae & baya & zoocoria & aves, mamíferos & intermedia \\
\hline Sapium macrocarpum Müll. Arg. & Euphorbiaceae & cápsula & zoocoria, barocoria & aves, gravedad & intermedia \\
\hline Cecropia peltata $\mathrm{L}$. & Cecropiaceae & $\begin{array}{l}\text { aquenios } \\
\text { agregados }\end{array}$ & zoocoria & aves, mamíferos & pionera \\
\hline Heliocarpus appendiculatus Turcz. & Malvaceae & cápsula & anemocoria & viento & pionera \\
\hline
\end{tabular}


et al., 2016). Esta especie está en la Lista Roja de especies arbóreas de los bosques de montaña de México en la categoría de Preocupación Menor (González-Espinosa et al., 2011), y no está listada en la Norma Oficial Mexicana NOM059-SEMARNAT-2010 (SEMARNAT, 2010).

El ramón, Brosimum alicastrum, presenta afinidad sucesional intermedia, es un árbol longevo de más de 20 $\mathrm{m}$ de altura, puede alcanzar diámetros a la altura del pecho de 1.5 m (Pennington y Sarukhán, 2005). Su presencia facilita la regeneración de árboles del dosel superior de bosques tropicales de México y Centroamérica (Pennington y Sarukhán, 2005). Crece vigorosamente bajo dosel relativamente denso (Laborde y Corrales-Ferrayola et al., 2012) y en suelos bien drenados (Mendoza-Arroyo et al., 2020). Los frutos de B. alicastrum son del tipo baya y los dispersan una gran variedad de aves y mamíferos (murciélagos, monos, ardillas, ratones; Berg, 1972). Es una especie sin aparente condición de amenaza, ya que no se encuentra mencionada en la Lista Roja de árboles del bosque de niebla en México (González-Espinosa et al., 2011), ni en la Norma Oficial Mexicana NOM-059-SEMARNAT-2010 (SEMARNAT, 2010).

El chileamate, Sapium macrocarpum, es una especie arbórea sucesionalmente intermedia que puede alcanzar $35 \mathrm{~m}$ de altura (CONABIO, 2020). Sus frutos son en forma de cápsula, que son dispersados principalmente por aves y mamíferos (zoocoria) y también por gravedad (N. RamírezMarcial, observación personal). Esta especie es utilizada como sombra en las plantaciones de café en la región del Soconusco, Chiapas (González-Espinosa et al., 2011). Se encuentra listada en la Norma Oficial Mexicana NOM-059-SEMARNAT-2010 (SEMARNAT, 2010) como especie amenazada, y de Preocupación Menor en la Lista Roja de árboles de bosques nublados de México (González-Espinosa et al., 2011).

\section{Muestreo de material vegetativo}

Las especies elegidas para este estudio estuvieron presentes en las tres localidades de muestreo, cuyos bosques tienen niveles de diversidad de especies similares, aunque las especies dominantes son diferentes. La especie más abundante en Emilio Rabasa es Pseudolmedia spuria (Sw.) Griseb., en Veinte Casas Louteridium donnell-smithii S. Watson; ambas especies son sucesionalmente tardías (Ra-
mírez-Marcial et al., 2017); en Nuevo San Juan Chamula la más abundante es la especie pionera $H$. appendiculatus. La distancia entre pares de localidades oscila entre 10 y $12 \mathrm{~km}$, lo que permitió asumir que el conjunto de individuos para cada especie de las tres localidades de estudio representa una población y las muestras de cada localidad representan subpoblaciones.

En cada una de las tres localidades se obtuvieron muestras de 20 individuos de cada especie. Los individuos se eligieron al azar, cuidando que hubiera una distancia entre ellos igual o mayor a 100 m (Nassar et al., 2011), para incrementar la probabilidad de colectar genotipos distintos. Por árbol (individuo) de cada especie se tomó una hoja joven de las ramas próximas al suelo y sin daño aparente, o cuando no fue posible acceder a las hojas (debido a la altura de algunos de los árboles $>1.5 \mathrm{~m}$ ), se obtuvo una muestra de cambium vascular del tallo. El cambium es el tejido meristemático específico de las plantas leñosas que está en regeneración continua (Plomion et al., 2001). Las muestras del cambium vascular $(n=78)$ se tomaron haciendo un corte en la corteza de $9 \mathrm{~cm}^{2}$ y se retiró con cuidado para reconocer el cambium y tomarlo asépticamente mediante un raspado con un hisopo o escalpelo esterilizados. Esta colecta no representa afectación alguna en el desarrollo individual o reproductivo de los individuos. Las muestras se conservaron en tubos Eppendorf con buffer CTAB 2× (bromuro de hexadeciltrimetilamonio). Las hojas tomadas de un total de 162 árboles de las diferentes especies se guardaron en sobres de papel secante y se etiquetaron para mantener la distinción del individuo de procedencia. Se transportaron en recipientes herméticos a una temperatura de $2{ }^{\circ} \mathrm{C}$ del campo al laboratorio de genética de El Colegio de la Frontera Sur (ECOSUR Unidad San Cristóbal), en donde se conservaron en congelación $\left(-70^{\circ} \mathrm{C}\right)$ hasta realizar la extracción de ADN. El total de muestras fue de 240 (78 de cambium, más 162 de hojas).

\section{Análisis genético}

La descripción de la variación genética de las especies de árboles se hizo con base en la variación nucleotídica de dos regiones espaciadoras internas transcritas de ADN nuclear ribosomal (ITS, por sus siglas en inglés, Internal Transcribed Spacer): ITS 1-2 (TCCGTAGGTGAACCTGCGG) - (GCTGCGTTCTT- 
CATCGATGC), e ITS 3-4 (GCATCGATGAAGAACGCAGC) - (TCCTCCGCTTATTGATATGC) que recuperan regiones de ADN de 290 pb y 330 pb, respectivamente (White et al., 1990). Este es un marcador con tasas de evolución lenta que se encuentra en hongos y probablemente en todas las especies de plantas vasculares, por lo que su principal uso es para la reconstrucción de filogenias y código de barras genético para plantas (China Plant BOL Group et al., 2011; Qin et al., 2017). En este estudio se decidió por el marcador ITS por su posible ubicuidad en diferentes grupos de flora vascular, y porque en ensayos piloto observamos variación nucleotídica, lo que permite obtener estimadores de diversidad genética para especies que carecen del diseño de marcadores específicos o de conocimiento previo de secuencias (Álvarez y Wendel, 2003). Por lo tanto, los resultados de variación genética poblacional que se obtienen con los ITS son válidos; en tanto se puedan desarrollar marcadores específicos.

La extracción de $A D N$ se realizó mediante el método CTAB 2x (Doyle y Doyle, 1987). La amplificación de ADN fue mediante la Reacción en Cadena de la Polimerasa (PCR), cuyo protocolo fue una amplificación de 35 ciclos que constó de una desnaturalización inicial de 2 a 3 min a $95{ }^{\circ} \mathrm{C}$, un alineamiento de $30 \mathrm{~s}$ a $57^{\circ} \mathrm{C}$, una extensión de 0.5 a 2 min a $72{ }^{\circ} \mathrm{C}$, una segunda desnaturalización de 30 s a $95{ }^{\circ} \mathrm{C}$ y una extensión final de $10 \mathrm{~min}$ a $72{ }^{\circ} \mathrm{C}$ (White et al., 1990). La cadena de nucleótidos producto de la PCR, se obtuvo mediante el método Sanger en un secuenciador ABI PRISM ANALYZER 3730XL (Macrogen Inc. Seoul, Korea), con la secuencia (oligo) iniciadora de ida ("forward").

\section{Análisis de secuencias y estimadores de diversidad}

Las secuencias se revisaron visualmente para detectar errores en un tamaño desproporcionado de la serie de nucleótidos y la presencia de dímeros con sobre-amplificación o copias del haplotipo blanco en una misma muestra. Cuando fue así, esta se descartó a pesar de que con ello se redujo el número de datos para el cálculo de parámetros genéticos. Las sucesiones de nucleótidos se editaron en CHROMAS v. 1.45 (McCarthy, 1998) y posteriormente se alinearon en el programa CRUSTALX v. 2.1 (Thompson et al., 1997).

Para determinar la diversidad genética capturada en las muestras, por localidad y por especie, se concatenaron las secuencias obtenidas para ambos marcadores ITS 1-2 e ITS 3-4, lo que permitió analizar una región concatenada de 620 pb para B. alicastrum, 628 pb para C. peltata, 595 para H. appendiculatus y 571 para S. macrocarpum. Se utilizó el programa DnaSP v. 5 (Rozas et al., 2003) para estimar el número de sitios segregados o polimórficos $(s)$, número de haplotipos $(h)$, el número promedio de las diferencias nucleotídicas entre cada par de secuencias $(K)$, la diversidad de haplotipos $(H d)$ y la diversidad de nucleótidos $(\pi)$ (Nei, 1987). Se aplicó la prueba D-Tajima (Tajima, 1989) para inferir si los sitios segregativos y el número promedio de diferencias nucleotídicas se ajustan a un modelo evolutivo neutral, o corresponden a cambios demográficos debido a presiones selectivas. Valores negativos de $D$-Tajima son esperados en poblaciones que han experimentado una expansión demográfica (crecimiento poblacional) relativamente reciente o como resultado de selección purificadora; los valores positivos indican procesos de selección balanceadora (o equilibrada) o reducción del tamaño poblacional (Tajima, 1989). La significancia estadística se obtuvo mediante la contrastación con el intervalo de confianza de $95 \%$, con base en la distribución beta de los valores de $D$ Tajima (Tajima, 1989).

Para determinar cómo se encuentra repartida la variación genética dentro y entre grupos de muestras por especie se realizaron análisis de varianza molecular por especie (AMOVA) en el programa Arlequín v. 3.1 (Excoffier et al., 2005), utilizando información de las secuencias de ITS 1-2 e ITS 3-4 concatenadas. El AMOVA subdivide la varianza molecular de manera jerárquica entre los grupos a comparar y a partir de esta distribución se calculó el estadístico $\Phi_{\text {st' }}$ que es análogo al estadístico Fst de Wright (Excoffier et al., 2005), el cual permite estimar el nivel de diferenciación de conjuntos de muestras, en este caso entre las tres localidades o subpoblaciones para cada especie y entre individuos (dentro de las subpoblaciones). Asimismo, se hizo un análisis de agrupación basado en un modelo Bayesiano y simulación mediante Cadenas Markovianas de Monte Carlo implementado en el programa Bayesian analysis of population Structure v. 5.3 (BAPS) (Corander et al., 2003). El número de poblaciones o grupos genéticos hipotéticos se estima asumiendo una población base panmíctica (representada por el conjunto total de la muestra) y dividida en $K$ subpoblaciones (Corander et al., 2003). Se declaró 
$K=3$ como límite superior de grupos genéticos o subpoblaciones, loci ligados, con intercambio genético entre los grupos genéticos. El periodo de inicio y simulación son los que el programa tiene por omisión (Corander et al., 2003). Adicionalmente, para identificar un posible patrón de la diversidad genética de cada especie se obtuvo, para cada una, la red de haplotipos no redundantes por el método de máxima parsimonia. Los parámetros declarados fueron épsilon igual a 0 , peso de transiciones-transversiones $1 / 1$ y el criterio de costo de conexión. La red de haplotipos se obtuvo mediante el programa NETWORK v. 10.1.0.0 (Polzin y Daneschmand, 2003).

\section{Resultados}

Se logró la extracción de ADN de 240 muestras (162 correspondieron a hoja y 78 a cambium). Sin embargo, la amplificación fue efectiva para un total de 103 secuencias concatenadas (número de acceso en GenBank MW494456MW494517, Apéndice; Benson et al., 2013). Se obtuvieron 19 secuencias de B. alicastrum, 32 de S. macrocarpum, 19 de $H$. appendiculatus y 33 de C. peltata (Cuadro 2), a partir de las cuales se reconocieron ocho haplotipos para $B$. alicastrum, cuatro de ellos fueron únicos. Se registraron 12 haplotipos para S. macrocarpum; nueve fueron únicos. En C. peltata se registraron seis haplotipos, solo uno fue único. En $H$. appendiculatus se detectaron cinco haplotipos, tres fueron únicos.

También los diferentes estimadores de diversidad fueron variables entre especies y entre localidades (Cuadro 2). El número de sitios segregativos fue ligeramente mayor en $S$. macrocarpum $(s=10)$ que en el de resto de las especies (entre 7 y 9). En esta misma especie se registró el

Cuadro 2: Parámetros de diversidad genética de Brosimum alicastrum Sw., Sapium macrocarpum Müll. Arg., Heliocarpus appendiculatus Turcz. y Cecropia peltata L., en tres localidades de la Reserva de la Biosfera Selva El Ocote (REBISO), Chiapas, México, con base en la concatenación de la región del ADN ribosomal nuclear ITS 1-2 e ITS 3-4. $N=$ tamaño de muestra (número de secuencias analizadas), $s=$ sitios segregativos, $h=$ número de haplotipos, $H d=$ diversidad de haplotídica, $\pi=$ diversidad nucleotídica, $K=$ diferencias nucleotídicas promedio, $D=$ prueba de Tajima; ${ }^{\text {Ns }}=$ No significativo; ${ }^{*}=P=0.001$; - = no se obtuvieron secuencias de la especie; -- = no se calculó por el bajo número de secuencias.

\begin{tabular}{|c|c|c|c|c|c|c|c|c|}
\hline Especie & Localidad/ total & $N$ & $s$ & $\boldsymbol{h}$ & $H d$ & $\pi$ & $\kappa$ & $D$ \\
\hline \multirow[t]{4}{*}{ Brosimum alicastrum Sw. } & Emilio Rabasa & 19 & 7 & 8 & 0.845 & 0.0041 & 1.649 & $-0.589^{\mathrm{NS}}$ \\
\hline & Veinte Casas & - & - & - & - & - & - & - \\
\hline & Nuevo San Juan & - & - & - & - & - & - & - \\
\hline & total & 19 & 7 & 8 & 0.845 & 0.0041 & 1.649 & $-0.589^{\mathrm{NS}}$ \\
\hline \multirow[t]{4}{*}{ Sapium macrocarpum Müll. Arg. } & Emilio Rabasa & 16 & 6 & 6 & 0.717 & 0.0039 & 1.508 & $-0.568^{\mathrm{NS}}$ \\
\hline & Veinte Casas & 11 & 3 & 5 & 0.818 & 0.0035 & 1.273 & $0.830^{\mathrm{NS}}$ \\
\hline & Nuevo San Juan & 5 & 4 & 4 & 0.900 & 0.0046 & 1.800 & $-0.410^{\mathrm{NS}}$ \\
\hline & total & 32 & 10 & 12 & 0.790 & 0.0047 & 1.730 & $-0.947^{\mathrm{NS}}$ \\
\hline \multirow[t]{4}{*}{ Cecropia peltata L. } & Emilio Rabasa & 17 & 2 & 3 & 0.404 & 0.0007 & 0.426 & $-0.696^{\mathrm{NS}}$ \\
\hline & Veinte Casas & 5 & 0 & 1 & 0 & 0 & 0 & 0 \\
\hline & Nuevo San Juan & 11 & 3 & 3 & 0.655 & 0.0022 & 1.418 & $-1.316^{\mathrm{NS}}$ \\
\hline & total & 33 & 8 & 6 & 0.735 & 0.0048 & 2.898 & $1.397^{\mathrm{NS}}$ \\
\hline \multirow[t]{4}{*}{ Heliocarpus appendiculatus Turcz. } & Emilio Rabasa & 10 & 7 & 3 & 0.511 & 0.0026 & 1.556 & $-1.573^{\mathrm{NS}}$ \\
\hline & Veinte Casas & 6 & 1 & 2 & 0.333 & 0.0005 & 0.333 & $-0.933^{\mathrm{NS}}$ \\
\hline & Nuevo San Juan & 3 & 2 & 3 & 1.0 & 0.002 & 1.333 & -- \\
\hline & total & 19 & 9 & 5 & 0.066 & 0.0059 & 3.474 & $-1.217^{\mathrm{NS}}$ \\
\hline $\begin{array}{l}\text { Total de muestras (especies y } \\
\text { localidades) }\end{array}$ & & 103 & 157 & 23 & 0.909 & 0.2406 & 76.271 & $5.089 *$ \\
\hline
\end{tabular}


mayor número de haplotipos (12), es la segunda en índice de diversidad de haplotipos ( $H d=0.790$ ) y la tercera en diversidad nucleotídica ( $\pi=0.0047$ ) y también en diferencias promedio nucleotídicas $(K=1.730)$. En $B$. alicastrum se observó el índice de diversidad de haplotipos más alto $(H d=$ 0.845; Cuadro 2).

En cuanto al estimador de diversidad nucleotídica $(\pi), H$. appendiculatus fue la más diversa y $B$. alicastrum la menos diversa. Con relación a las diferencias promedio de diversidad $(K), H$. appendiculatus es la más diversa ( $K=$ 3.474 ) y la menos diversa es $B$. alicastrum ( $K=1.649$ ). Los estimadores de diversidad genética para poblaciones fueron en forma general más altos en la localidad de Emilio Rabasa, seguido de Nuevo San Juan y Veinte Casas para todas las especies (Cuadro 2).

La distribución de la diversidad genética observada en S. macrocarpum, de acuerdo con el AMOVA, fue $77.8 \%$ entre individuos y $22.2 \%$ entre localidades o subpoblaciones (Cuadro 3), con un valor de diferenciación genética de $\Phi_{\text {st }}=0.22$. En las especies $H$. appendiculatus y $C$. peltata, se observó que el mayor porcentaje de variación fue entre las poblaciones (>80\%), con una estimación de diferenciación genética de $\Phi_{\text {st }}=0.81$ para $H$. appendiculatus y de $\Phi_{\text {st }}=0.83$ para $C$. peltata. Este análisis no se realizó en $B$. alicastrum debido a que se tuvieron datos solo para una localidad. El análisis de agrupación basado en un modelo Bayesiano reconoció tres grupos genéticos para $C$. peltata. Las muestras de Veinte Casas y Nuevo San Juan se incluyeron en un mis- mo grupo genético (Grupo 3), mientras que las muestras de Emilio Rabasa constituyeron otro grupo genético (Grupo 1) a excepción de un individuo que se reconoce como parte del Grupo 2 (Fig. 2A). En H. appendiculatus se identificaron dos grupos, Nuevo San Juan y Veinte Casas se asignaron a un mismo grupo genético (Grupo 1), mientras que Emilio Rabasa con una muestra de Nuevo San Juan constituyó el Grupo 2 (Fig. 2B). Para S. macrocarpum se observaron dos grupos, aunque uno de ellos se constituyó de únicamente un individuo (Grupo 2) (Fig. 2C)

La prueba de Tajima $(D)$ fue negativa y no significativa para casi todas las poblaciones, excepto para S. macrocarpum en Veinte Casas en donde fue positiva, pero no significativa. Para el conjunto total de muestras por especies el valor de $D$-Tajima resultó negativo y no significativo (Cuadro 2), lo que sugiere que los cambios nucleotídicos se ajustan a un modelo de evolución neutral.

La red de haplotipos para $B$. alicastrum mostró una red de haplotipos simple, con una o dos mutaciones entre los distintos haplotipos (Fig. 3A). En el caso de S. macrocarpum, la red muestra que el haplotipo más frecuente $(\mathrm{H} 2)$ se encontró en todas las localidades, la mayoría de los haplotipos con una frecuencia menor $(<2)$ se registraron solo en Emilio Rabasa. El análisis muestra que para establecer la relación genealógica entre los haplotipos $\mathrm{H} 2$ y H5, H12, H7 de S. macrocarpum, se requiere de un haplotipo ancestral hipotético no identificado (H) en este estudio (Fig. 2B). Cuatro haplotipos de C. peltata se registraron solo en Emilio

Cuadro 3: Análisis de varianza molecular para secuencias de ITS 1-2 y 3-4 en tres especies de árboles de la Reserva de la Biosfera Selva El Ocote (REBISO), Chiapas, México.

\begin{tabular}{|c|c|c|c|c|c|}
\hline Especie & Fuente de variación & $\begin{array}{c}\text { Grados de } \\
\text { libertad }\end{array}$ & $\begin{array}{l}\text { Suma de } \\
\text { cuadrados }\end{array}$ & $\begin{array}{c}\text { Componente de } \\
\text { varianza }\end{array}$ & \% de variación \\
\hline \multirow[t]{3}{*}{ Sapium macrocarpum Müll. Arg. } & entre subpoblaciones & 2 & 5.536 & 0.209 & 22.20 \\
\hline & dentro de las subpoblaciones & 29 & 21.276 & 0.734 & 77.80 \\
\hline & total & 31 & 26.812 & 0.943 & \\
\hline \multirow[t]{3}{*}{ Heliocarpus appendiculatus Turcz. } & entre subpoblaciones & 2 & 23.696 & 2.001 & 80.89 \\
\hline & dentro de las subpoblaciones & 16 & 7.567 & 0.472 & 19.11 \\
\hline & total & 18 & 31.263 & 2.474 & \\
\hline \multirow[t]{3}{*}{ Cecropia peltata L. } & entre subpoblaciones & 2 & 35.861 & 1.774 & 83.52 \\
\hline & dentro de las subpoblaciones & 30 & 10.503 & 0.350 & 16.48 \\
\hline & total & 32 & 46.364 & 2.124 & \\
\hline
\end{tabular}


(A) Cecropia peltata L.

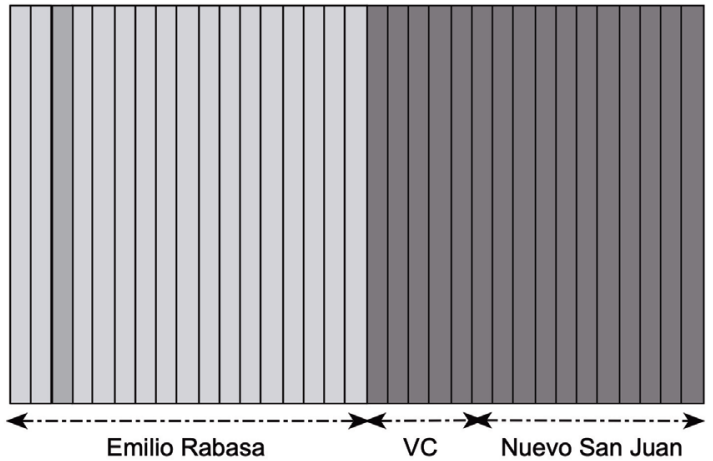

(B) Heliocarpus appendiculatus Turcz.

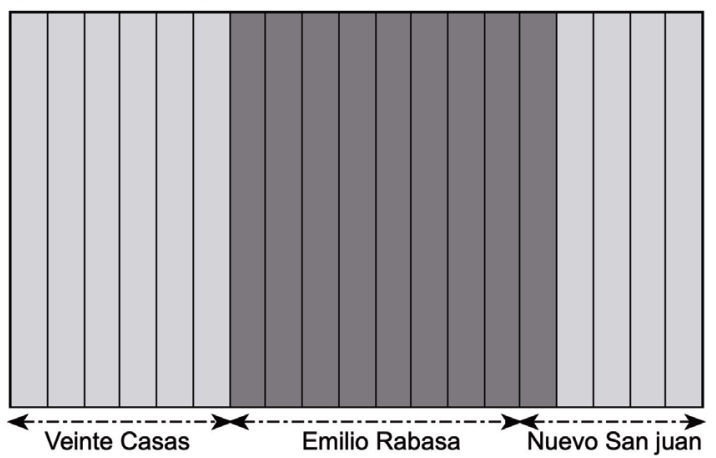

(C) Sapium macrocarpum Müll. Arg.
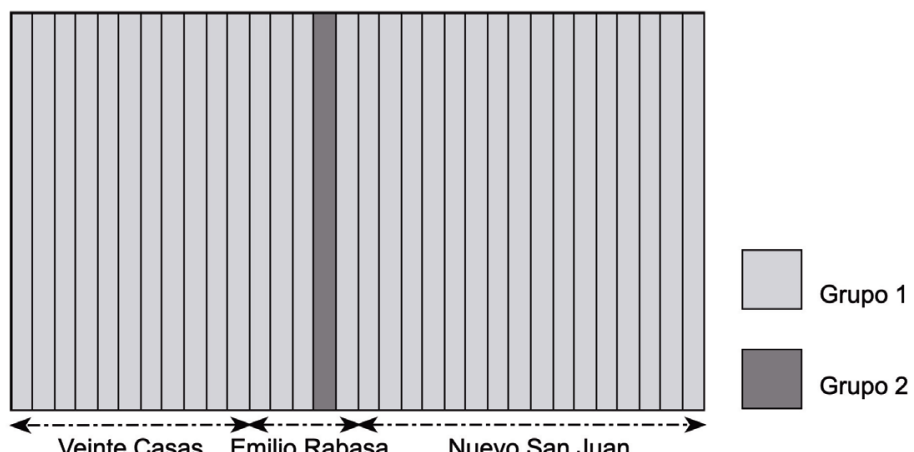

Figura 2: Análisis de agrupación, para tres especies de árboles tropicales, Brosimum alicastrum Sw., Sapium macrocarpum Müll. Arg., Heliocarpus appendiculatus L. y Cecropia peltata Turcz., basado en un modelo Bayesiana implementado en el programa BAPS v. 5.3 (Corander et al., 2003). Cada barra representa un individuo y el color de la barra indica al grupo genético al que pertenece.

Rabasa, uno de ellos fue el más frecuente $(\mathrm{H} 1)$, y el que le sigue en frecuencia, $\mathrm{H} 2$, en dos localidades, Nuevo San Juan y Veinte Casas. El haplotipo H5 únicamente se observó en Nuevo San Juan y se deriva de un haplotipo no identificado en este estudio (H; Fig. 3C). Para el caso de H. appendiculatus la red mostró también cierta asociación de los haploti- pos con las localidades. Finalmente, resalta la cantidad de mutaciones (6) que se requieren para derivar el haplotipo $\mathrm{H} 3$ del H2, así como el hecho de que el haplotipo H3 solo se registró en Nuevo San Juan (Fig. 3D).

\section{Discusión}

No obstante que el marcador ITS presenta una tasa de evolución baja y se conserva en los linajes (Álvarez y Wendel, 2003), se observó variación nucleotídica en las poblaciones en las cuatro especies estudiadas. Esto fue útil para obtener una estimación aproximada de la diversidad genética de elementos arbóreos de la REBISO, y con ello se tuvo un acercamiento a la diversidad biológica de la reserva a nivel genético molecular (Rodríguez-Correa et al., 2017). Los datos genéticos que se obtienen con los ITS se han utilizado escasamente para estudios poblacionales considerando escalas geográficas amplias, pero que incluyen sitios cercanos (Ornelas et al., 2016). En el presente estudio se encontró variación nucleotídica en las secuencias concatenadas de ITS, con lo que fue posible obtener parámetros de diversidad genética, así como la identificación de variación genética entre subpoblaciones o localidades para algunas de las especies, a pesar de las cortas distancias geográficas, la distancia promedio entre pares de localidades es de $11 \mathrm{~km}$.

La mayor diversidad genética se registró en S. macrocarpum, especie sucesionalmente intermedia, cuyos frutos son dispersados principalmente por aves, y también por gravedad; seguida de $H$. appendiculatus y C. peltata, especies pioneras con síndrome de dispersión anemócora y zoocora, respectivamente. La especie con la menor diversidad genética, debido probablemente el tamaño de muestra reducido, fue $B$. alicastrum, especie persistente durante la sucesión, cuyos frutos los dispersan aves y mamíferos terrestres y voladores (Galindo-González, 1998). La diferenciación genética entre poblaciones observada fue moderada para S. macrocarpum y alta $(F \sim 0.80)$ para las dos especies pioneras, $H$. appendiculatus y $C$. peltata.

En general, se registró la mayor diversidad genética y menor diferenciación entre poblaciones de S. macrocarpum, una de las especies de sucesión intermedia. En B. alicastrum, otra especie de sucesión avanzada, observamos la menor diversidad nucleotídica, pero no fue posible hacer estimaciones de diferenciación genética, ya que solo se lo- 

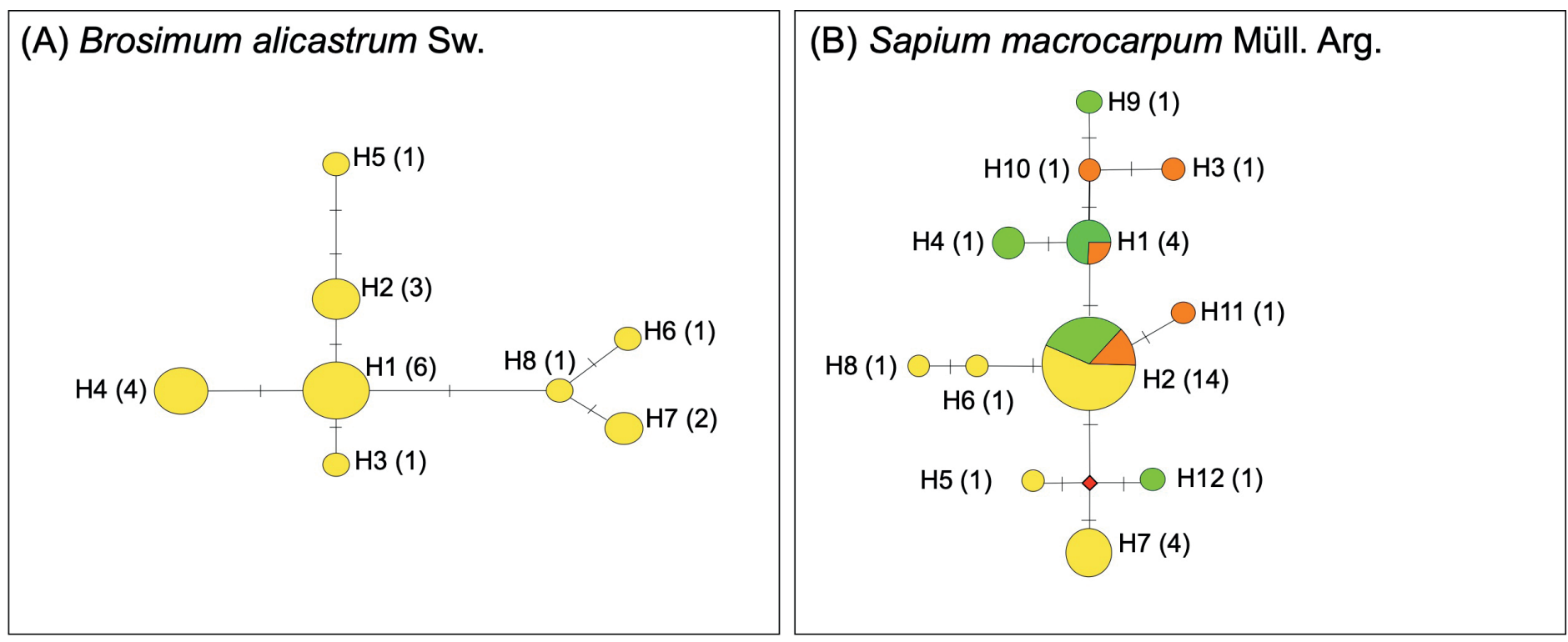

(C) Cecropia peltata L.

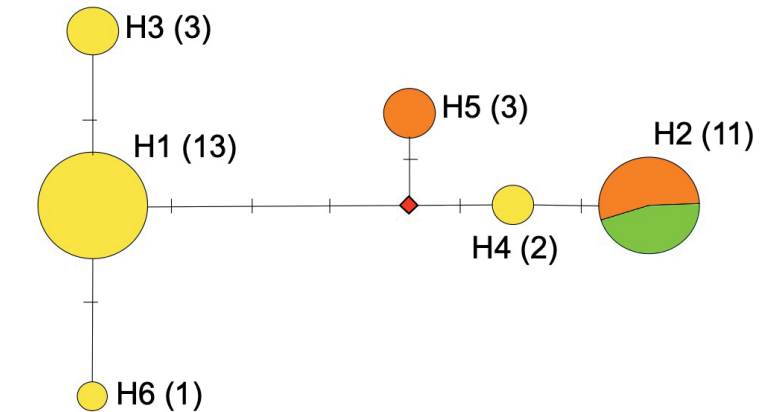

(D) Heliocarpus appendiculatus Turcz.

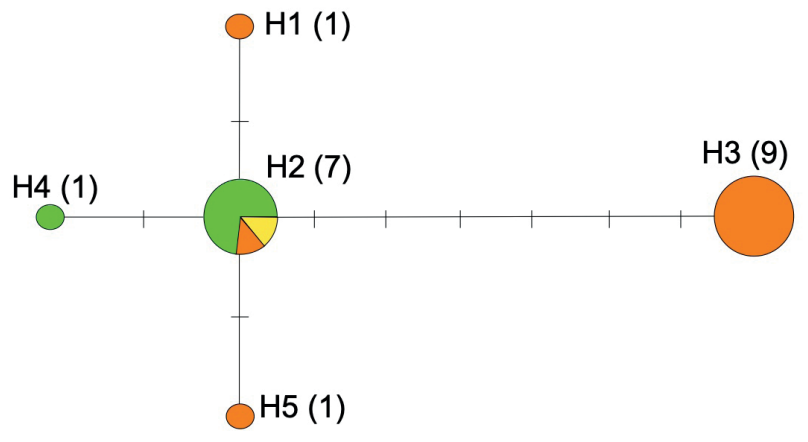

Nuevo San Juan
Emilio Rabasa

\section{Veinte Casas}

Figura 3: Red de haplotipos de: A. Brosimum alicastrum Sw.; B. Sapium macrocarpum Müll. Arg.; C. Cecropia peltata Turcz.; D. Heliocarpus appendiculatus L. registrados en muestras tomadas en cuatro localidades de la Reserva de la Biosfera Selva El Ocote (REBISO), Chiapas, México. Cada círculo representa un haplotipo, el tamaño refiere a su frecuencia (también se presenta entre paréntesis) y los colores indican la localidad. Los rombos rojos son haplotipos ancestrales hipóteticamente necesarios para derivar los haplotipos observados.

gró la amplificación de las muestras tomadas en la localidad de Emilio Rabasa, lo que seguramente resultó en una deficiencia en el muestreo de alelos. No obstante, los valores del número segregativo $(s)$, la diversidad nucleotídica $(p)$ e índice de diversidad de haplotipos estuvieron en el orden de magnitud de los registrados por Cruz-Salazar et al. (2021), en muestras tomadas también en la REBISO para relacionar la diversidad genética con la riqueza de especies en cuatro comunidades locales de árboles de la reserva.

En otras especies de árboles neotropicales de sucesión intermedia y tardía como Hymenaea courbaril L. y Aniba rosaeodora Ducke, se ha observado alta diversidad genética medida como heterocigosidad esperada con marcadores microsatélites $\left(H_{e}=0.813\right.$ y $H_{e}=0.807$, respectiva- 
mente) (Feres et al., 2009; Lozano et al., 2011; Angrizani et al., 2013). En nuestro estudio los estimadores proximales de la diversidad genética son el índice de diversidad haplotídica $(H d)$ y nucleotídica $(\pi)$. En particular $\pi$ es una medida de heterocigosidad a nivel de secuencias (Nei, 1987). Los valores observados entre 0.0041 y 0.0059 se pueden considerar de moderados a altos, ya que representan una tasa de cambio de nucleótidos relativamente alta en una secuencia de ADN de 578 pb y que se reconoce altamente conservada (Álvarez y Wendel, 2003).

Con base en el estadístico de $D$-Tajima se sugiere que los cambios en los sitios segregativos corresponden a cambios esperados bajo un modelo de evolución neutral, i.e. las mutaciones en las secuencias son aleatorias y han tenido un efecto neutro en la supervivencia y reproducción de las especies (Tajima, 1989). Los valores negativos apuntan hacia un cambio demográfico propio de una selección balanceada (polimorfismo estable). Este resultado puede proponerse como congruente con la observación de que en los sitios de estudio hay una comunidad vegetal en condiciones óptimas de desarrollo estructural (Ramírez-Marcial et al., 2017).

Los resultados de diferenciación $\left(\Phi_{\text {st }}\right)$ y variación genética entre poblaciones no coinciden con la hipótesis de que las especies de vida corta, como pueden ser las sucesionalmente pioneras en comparación con las sucesionalmente intermedias, presentan menor variación entre poblaciones que las especies de larga vida (Hamrick et al., 1992). Cecropia peltata y $\mathrm{H}$. appendiculatus son especies sucesionalmente pioneras, cuyos estimadores de diferenciación genética $\left(\Phi_{\mathrm{st}}\right)$ fueron mayores que en la especie de afinidad sucesional intermedia (S. macrocarpum). Consistentemente el análisis de agrupación basado en un modelo Bayesiano mostró al menos dos grupos genéticos en $C$. peltata y $\mathrm{H}$. appendiculatus y prácticamente un solo grupo para S. macrocarpum. Asimismo, el análisis de agrupación indica que para las dos especies pioneras las muestras de Veinte Casas y Nuevo San Juan constituyeron un mismo grupo genético, y otro, las muestras de Emilio Rabasa. La diferenciación genética entre localidades se muestra también a través de la distribución de los haplotipos. En C. peltata los haplotipos $\mathrm{H} 3, \mathrm{H} 1, \mathrm{H} 6$ y $\mathrm{H} 2$ se presentaron solo en Emilio Rabasa y en $\mathrm{H}$. appendiculatus sus haplotipos $\mathrm{H} 1, \mathrm{H} 3$ y H5 únicamente en Nuevo San Juan. Estas especies, al ser pioneras, requieren de la apertura de claros para su establecimiento exitoso (Garay-Arroyo y Álvarez-Buylla, 1997). Son generalmente especies de vida corta ( $<40$ años) y alcanzan su edad reproductiva entre 7 y 10 años, por lo que la dispersión de semillas es importante para la continuidad de las especies. En los sitios perturbados o "acahuales", se espera que las especies pioneras estén en densidades más altas que en las áreas con bosques maduros, y esto permite que la variación genética tenga una distribución más homogénea en el espacio (Eguiarte et al., 1992; Álvarez-Buylla y Garay-Arroyo, 1994). Las especies pioneras persisten en las selvas conservadas por la formación de claros que ocurre en diferentes momentos y pueden ser también filtros distintos por la heterogeneidad microambiental que puede ocurrir a escalas locales (Dakwa et al., 2020). Esto genera una estructura genética a escalas geográficas pequeñas, como se observó para $H$. appendiculatus y C. peltata, que es a su vez consistente con el estudio de Chávez-Pesqueira y NúñezFarfán (2016) con la especie pionera de claros Carica papaya L. (Caricaceae) en el sur de México. Por otro lado, en paisajes modificados por las actividades humanas, las especies pioneras llegan a presentar altas tasas de dispersión, como por ejemplo en Miconia affinis D.C. (Melastomataceae) en Panamá (Castilla et al., 2016), lo que promueve que espacialmente sus poblaciones mantengan cohesión genética. La colecta de muestras de $C$. peltata y $H$. appendiculatus se realizó dentro de parches con vegetación madura y se evitó adquirir material vegetativo de árboles próximos para disminuir la probabilidad de colectar individuos emparentados. Es posible que al estar inmersos en bosques con alta riqueza de especies de árboles (Ramírez-Marcial et al., 2017), el intercambio genético entre poblaciones sea reducido y por ello se detectó menor diversidad y más diferenciación genética entre poblaciones. Esa diversidad arbórea limita el desarrollo poblacional de $H$. appendiculatus y $C$. peltata, lo que genera una diferenciación genética entre las poblaciones $\left(\Phi_{\mathrm{st}}=0.81\right)$ y una distribución heterogénea de los haplotipos.

Un resultado inesperado es que la mayoría de los haplotipos de S. macrocarpum fueron únicos (7 de 10 haplotipos se registraron solo una vez) y el haplotipo más frecuente se registró en todas las localidades. Esto puede significar 
que hay una tasa evolutiva relativamente rápida, pero la distribución de los haplotipos entre las localidades puede estar relacionada a una dispersión limitada y azarosa, de manera que se observó que la distribución espacial de los haplotipos no es homogénea. Significa que los haplotipos no tuvieron la misma oportunidad de llegar a cada localidad simplemente por azar, de lo contrario se habrían observado en todas las localidades. Por ejemplo, los haplotipos H5, H6 y H7 se encontraron únicamente en Emilio Rabasa. No obstante, el análisis de agrupación Bayesiano mostró un grupo genético para S. macrocarpum, lo que indica una cohesión genética ancestral entre los individuos muestreados en las distintas localidades.

Hamrick et al. (1992) mostraron que las especies cuyos frutos o semillas son dispersados por animales, por ser consumidas por ellos, tienen mayor heterocigosidad y sus niveles de diferenciación genética (estimado como estadístico $F_{S T}$ de Wright) son mayores que en especies cuyas semillas son dispersadas por el viento. La regularidad del movimiento y la distancia que recorre el dispersor, que consume los frutos o semillas, pueden generar una homogeneidad genética entre las poblaciones de plantas (Loveless y Hamrick, 1984; Nathan y Muller-Landau, 2000). En este estudio encontramos que las especies pioneras, tanto las dispersadas por el viento como por animales, tuvieron la mayor diferenciación genética entre poblaciones, aunque su nivel de diversidad fue relativamente similar entre ellas. Aún para las especies que podrían ser dispersadas a grandes distancias por las aves, como S. macrocarpum y $C$. peltata, se encontró una diferenciación genética de consideración. Por lo tanto, es posible que el síndrome de dispersión influye en los patrones de diversidad genética; sin embargo, no es el único factor y posiblemente las condiciones físicas y ambientales locales, por ejemplo, el suelo, la radiación solar y la humedad pueden influir en el establecimiento de ciertos genotipos. Los sitios de estudio se consideran en buen estado de conservación (Ramírez-Marcial et al., 2017; Cruz-Salazar et al., 2021) y posiblemente con un ambiente físico al interior del bosque relativamente estable. No obstante, a nivel micro-espacial (decenas de $\mathrm{km}$ ) puede haber diferencias en temperatura de $1-2{ }^{\circ} \mathrm{C}$, y también la humedad relativa es variable a escalas geográficas pequeñas (Muñoz-Alonso et al., 2017). Además, la precipi- tación media anual es heterogénea a escalas relativamente cortas (Manzanilla-Quiñones y Aguirre-Calderón, 2017). Estas condiciones pueden afectar el establecimiento de nuevos individuos de las especies, tanto de árboles del sitio como del ingreso a través de dispersión de sus semillas. Por otro lado, la forma de dispersión de polen y el sistema de apareamiento puede ser determinante del patrón de diversidad genética observado (Loveless y Hamrick, 1984; Gamba y Muchhala, 2020). Se sabe que la predictibilidad de los síndromes de polinización es mayor en especies tropicales dependientes de polinizadores especializados (Rosas-Guerrero et al., 2014). Las especies de plantas con polinización por insectos pequeños y sistemas de reproducción mixta presentan poblaciones más diferenciadas (Gamba y Muchhala, 2020). El sistema de reproducción es desconocido para las especies incluidas en el presente trabajo, aspectos que deberían abordarse en futuros estudios para incrementar nuestro conocimiento biológico y entender mejor los patrones de diversidad genética. La polinización de $B$. alicastrum y C. peltata es probablemente por viento (Berg, 1972; Berg et al., 2005), lo que supondría un libre intercambio de alelos siempre y cuando la diversidad de árboles de las selvas que habitan no represente barreras del movimiento del polen. La diferenciación entre grupos de especies se debe a múltiples estrategias de crecimiento y de diferentes síndromes de polinización, lo cual representa una posible vía para la coexistencia de una alta diversidad de especies de una comunidad de árboles dada (Cortés-Flores et al., 2017), y posiblemente también de la diversidad genética que se observó en las especies del presente estudio. El síndrome de dispersión de las plantas se infiere a partir de la morfología de los frutos (Ibarra-Manríquez y CornejoTenorio, 2010). Sin embargo, no es suficiente para determinar de forma fiable a los dispersores efectivos, así como los alcances geográficos de su dispersión, ya que la interacción planta-dispersor puede variar según la estacionalidad, disponibilidad de recursos y de las necesidades dietéticas de los dispersores (Muller-Landau y Hardesty, 2005). La intervención de múltiples características morfológicas y ecológicas en la determinación de los síndromes de dispersión, y las propias de los dispersores, posiblemente contribuye a que la relación entre la diversidad genética y el síndrome de dispersión sea difícil de establecer (ver Gelmi-Candusso 
et al., 2017). No obstante que solo observamos dos síndromes de dispersión, zoocoria y anemocoria, y que difieren poco en los niveles de diversidad, no se descarta una posible relación entre el síndrome de dispersión y los patrones de diversidad genética; por lo que sería valioso confirmarla en estudios posteriores con más especies y marcadores que recuperen una mayor variación genética.

Otro aspecto por abordar a futuro es conocer el efecto de la degradación del hábitat que se observa en la REBISO (Flamenco-Sandoval et al., 2007) y la fragmentación en la reducción de los agentes de dispersión con posibles consecuencias en la estructura genética de las plantas (Cramer et al., 2007), y en particular para B. alicastrum, S. macrocarpum y C. peltata. Una dispersión limitada de semillas o polen conduce a una mayor estructuración genética de las poblaciones, por el reducido flujo genético (Lasso et al., 2011), que puede ocurrir para algunas especies, aunque cabe hacer notar para otras, la presencia de grandes áreas abiertas favorece la dispersión de alelos (Kamm et al., 2010). Las especies que se dispersan por el viento como $H$. appendiculatus y $B$. alicastrum, son menos susceptibles a los cambios en el paisaje (Howe, 2016) y su evolución parece tener relación con un movimiento más bien aleatorio dentro de la REBISO.

El presente estudio aporta elementos para considerar la importancia de planificar estrategias de conservación que permitan mantener la variación genética que naturalmente ocurre en la REBISO. La recuperación de poblaciones de manera asistida en áreas degradadas por actividades humanas o por incendios forestales, que han ocurrido en la REBISO (Maldonado Méndez et al., 2009), deberá contemplar la inclusión de variación genética que incremente la probabilidad del establecimiento y viabilidad a largo plazo de las poblaciones de árboles tropicales que se forman artificialmente a través de estrategias de recuperación o restauración.

En conclusión, S. macrocarpum (especie sucesionalmente intermedia con dispersión zoocora) es la especie más diversa, con variación genética entre poblaciones moderada, mientras que las especies menos diversas, pero con mayor variación genética entre poblaciones, fueron las especies pioneras $H$. appendiculatus y $C$. peltata con dispersión anemócora y zoocora, respectivamente.

\section{Contribución de autores}

LRM, MZLL y NRM concibieron y diseñaron el estudio. MZLL y MGB adquirieron y analizaron los datos. $L R M, C L$ y NRM ayudaron en la interpretación de la información. MZLL escribió una versión preliminar del manuscrito. LRM, NRM y CL redactaron la versión final. Todos los autores contribuyeron a la discusión, revisión y aprobación del manuscrito final.

\section{Financiamiento}

Este estudio fue apoyado por el Consejo Nacional de Ciencia y Tecnología (CONACYT), con financiamiento a través del proyecto 214650-Vulnerabilidad social y biológica ante el cambio climático en la Reserva de la Biosfera Selva El Ocote (REBISO), y a través de la beca para estudios de maestría a MZLL (573950).

\section{Agradecimientos}

A Miguel Martínez Icó y Alfonso Luna Gómez, por su apoyo en el trabajo de campo. Al personal de la Reserva de la Biosfera Selva EI Ocote (REBISO) y comunidades locales por facilitar el acceso a las áreas de estudio.

\section{Literatura citada}

Álvarez-Buylla, E. R. y A. Garay-Arroyo. 1994. Population genetic structure of Cecropia obtusifolia, a tropical pioneer tree. Evolution 48(2): 437-453. DOI: https://doi. org/10.1111/j.1558-5646.1994.tb01322.x

Álvarez, I. y J. F. Wendel. 2003. Ribosomal ITS sequences and plant phylogenetic inference. Molecular Phylogenetics and Evolution 29(3): 417-434. DOI: https://doi.org/10.1016/s10557903(03)00208-2

Angrizani, R. C., L. A. S. Contim y M. R. Lemes. 2013. Development and characterization of microsatellite markers for the endangered Amazonian Tree Aniba rosaeodora (Lauraceae). Applications in Plant Sciences 1(9): 1200516. DOI: https://doi. org/10.3732/apps.1200516

Benson, D. A., M. Cavanaugh, K. Clark, I. Karsh-Mizrachi, D. J. Lipman, J. Ostell, E. W. Sayers. 2013. GenBank. Nucleic Acids Research 41 (D1): D36-D42. DOI: https://doi.org/10.1093/nar/gks1195

Berg, C. C. 1972. Brosimum alicastrum Sw. subsp. alicastrum. Flora Neotropica 7: 170-171.

Berg, C., P. F. Rosselli y D. Davidson. 2005. Cecropia. Flora Neotropica 94: 1-230. 
Castilla, A. R., N. Pope, R. Jaffé y S. Jha. 2016. Elevation, not deforestation, promotes genetic differentiation in a pioneer tropical tree. PloS ONE 11(6): e0156694. DOI: https://doi. org/10.1371/journal.pone.0156694

Chávez-Pesqueira, M. y J. Núñez-Farfán. 2016. Genetic diversity and structure of wild populations of Carica papaya in northern Mesoamerica inferred by nuclear microsatellites and chloroplast markers. Annals of Botany 118(7): 1293-1306. DOI: https://doi.org/10.1093/aob/mcw183

China Plant BOL Group, L. De-Zhu, G. Lian-Ming, L. Hong-Tao, H. Wang, G. Xue-Jun, L. Jian-Quan, C. Zhi-Duan, Z. Shi-Liang, C. Shi-Lin, Y. Jun-Bo, F. Cheng-Xin, Z. Chun-Xia, Y. Hai-Fei, Z. Ying-Jie, S. Yong-Shuai, C. Si-Yun, Z. Lei, W. Kun, Y. Tuo y D. Guang-Wen. 2011. Comparative analysis of a large dataset indicates that internal transcribed spacer (ITS) should be incorporated into the core barcode for seed plants. Proceedings of the National Academy of Sciences 108(49): 1964119646. DOI: https://doi.org/10.1073/pnas.1104551108

CONABIO. 2020. EncicloVida. Comisión Nacional para el Conocimiento y Uso de la Biodiversidad (CONABIO). Cd. Mx., México. http://www.enciclovida.mx (consultado diciembre de 2020).

Corander, J., P. Waldmann y M. J. Sillanpää. 2003. Bayesian Analysis of genetic differentiation between populations. Genetics 163(1): 367-374. DOI: https://doi.org/10.1093/genetics/163.1.367

Cornelis, B., P. Franco y D. W. Davidson. 2005. Cecropia. Flora Neotropica 94: 1-230.

Cortés-Flores, J., K. B. Hernández-Esquivel, A. González-Rodríguez y G. Ibarra-Manríquez. 2017. Flowering phenology, growth forms, and pollination syndromes in tropical dry forest species: Influence of phylogeny and abiotic factors. American Journal of Botany 104(1): 39-49. DOI: https://doi. org/10.3732/ajb.1600305

Cramer, J. M., R. C. G. Mesquita y G. B. Williamson. 2007. Forest fragmentation differentially affects seed dispersal of large and small-seeded tropical trees. Biological Conservation 137(3): 415-423. DOI: https://doi.org/10.1016/j.biocon.2007.02.019

Cruz-Salazar, B., L. Ruiz-Montoya, N. Ramírez-Marcial y M. García-Bautista. 2021. Relationship between genetic variation and diversity of tree species in tropical forests in the El Ocote Biosphere Reserve, Chiapas, Mexico. Tro- pical Conservation Science 14: 1-14. DOI: https://doi. org/10.1177/1940082920978143

Dakwa, K. B., B. Opoku y J. Toku. 2020. The role of size and number of forest patches in the conservation of bird species in a fragmented landscape. Ostrich 91(4): 292-298. DOI: https:// doi.org/10.2989/00306525.2020.1792569

Dalling, J. W. 2002. Ecología de las semillas. In: Guariguatta M. R. y G. H. Kattan (eds.). Ecología y conservación de bosques neotropicales. LUR Ediciones. Cartago, Costa Rica. Pp. 299-328.

Doyle, J. J. y J. L. Doyle. 1987. Isolation of DNA from small amounts of plant tissues. BRL Focus 12(1): 13-15.

Eguiarte, L. E., N. Perez y D. Piñero. 1992. Genetic structure, outcrossing rate and heterosis in Astrocaryum mexicanum (tropical palm): implications for evolution and conservation. Heredity 69: 217-228. DOI: https://doi.org/10.1038/ hdy.1992.119

Excoffier, L., G. Laval y S. Schneider. 2005. Arlequin (version 3.0): An integrated software package for population genetics data analysis. Evolutionary Bioinformatics 1: 47-50. DOI: https://doi.org/10.1177/117693430500100003

FAO. 2014. The state of the world's forest genetic resources. Commission on genetic resources for food and agriculture-Food and Agriculture Organization of the United Nations (FAO). Rome, Italy. http://www.fao.org/3/a-i3825e.pdf (consultado mayo de 2021).

Feres, J. M. Guidugli M. C., M. A. Mestriner, Sebbenn A. M., Ciampi A. Y. y A. L. Alzate-Marin. 2009. Microsatellite diversity and effective population size in a germoplasm bank of $\mathrm{Hy}$ menaea courbaril var. stilbocarpa (Leguminosae), an endangered tropical tree: recommendations for conservation. Genetic Resources and Crop Evolution 56: 797-807. DOI: https://doi.org/10.1007/s10722-008-9402-2

Figueroa-Esquivel, E. M., F. Puebla-Olivares, L. E. Eguiarte y J. NúñezFarfán. 2010. Genetic structure of a bird-dispersed tropical tree (Dendropanax arboreus) in a fragmented landscape in Mexico. Revista Mexicana de Biodiversidad 81(3): 789-800. DOI: https://doi.org/10.22201/ib.20078706e.2010.003.649

Figueroa, J.A. y C. Vázquez-Yanes. 2002. Efecto de la calidad de la luz sobre la germinación de semillas en el árbol pionero tropical Heliocarpus appendiculatus (Tiliaceae). Revista de Biología Tropical 50(1): 31-36.

Flamenco-Sandoval, A., M. Martínez Ramos y O. R. Masera. 2007. Assessing implications of land-use and land-cover change 
dynamics for conservation of a highly diverse tropical rain forest. Biological Conservation 138(1-2): 131-145. DOI: https://doi.org/10.1016/j.biocon.2007.04.022

Frankham, R. 1995. Conservation genetics. Annual Review of Genetics 29: 305-327. DOI: https://doi.org/10.1146/annurev. ge.29.120195.001513

Galindo-González, J. 1998. Dispersión de semillas por murciélagos: su importancia en la conservación y regeneración del bosque tropical. Acta Zoológica Mexicana (N.S.) 73: 57-74.

Gamba, D. y N. Muchhala. 2020. Global patterns of population genetic differentiation in seed plants. Molecular Ecology 29(18): 3413-3428. DOI: https://doi.org/10.1111/mec.15575

Garay-Arroyo, A. y E. R. Álvarez-Buylla. 1997. Isozyme variation in a tropical pioneer tree species (Cecropia obtusifolia, Moraceae) with high contents of secondary compounds. Biotropica 29(3): 280-290. DOI: https://doi. org/10.1111/j.1744-7429.1997.tb00429.x

Gelmi-Candusso, T. A., E. W. Heymann y K. Heer. 2017. Effects of zoochory on the spatial genetic structure of plant populations. Molecular Ecology 26(21): 5896-5910. DOI: https:// doi.org/10.1111/mec.14351

GenBank. 2021. National Center for Biotechnology Information, U.S. National Library of Medicine. Rockville Pike, MD, USA. http://www.ncbi.nlm.nih.gov/genbank/.

Gómez-Pompa, A. 1971. Posible papel de la vegetación secundaria en la evolución de la flora tropical. Biotropica 3(2): 125135. DOI: https://doi.org/10.2307/2989816

González-Espinosa, M., J. A. Meave, F. Lorea-Hernández, G. Ibarra-Manríquez y A. C. Newton. 2011. The red list of Mexican cloud forest trees. Fauna and Flora International. Cambridge, UK. 124 pp.

Guariguatta, M. R. y R. Ostertag. 2002. Sucesión secundaria. In: M. Guariguatta y G. Kattan (eds.). Ecología y conservación de Bosques Neotropicales. LUR Press. Cartago, Costa Rica. Pp. 559-624

Hamrick, J. L. 2004. Response of forest trees to global environmental changes. Forest Ecology and Management 197(1-3): 323-335. DOI: https://doi.org/10.1016/j.foreco.2004.05.023

Hamrick, J. L. y M. J. W Godt. 1996. Effects of life history traits on genetic diversity in plant species. Philosophical Transaction of Royal Society of London, Series B: Biological Sciences 351(1345): 1291-1298. DOI: https://doi.org/10.1098/ rstb.1996.0112
Hamrick, J. L., W. M. J. Godt y S. L. Sherman-Broyles. 1992. Factors influencing levels of genetic diversity in woody plant species. New Forests 6(1-4): 95-124. DOI: https://doi. org/10.1007/BF00120641

Howe, H. F. 2016. Making dispersal syndromes and networks useful in tropical conservation and restoration. Global Ecology and Conservation 6: 152-178. DOI: https://doi. org/10.1016/j.gecco.2016.03.002

Hughes, A. R., B. D. Inouye, M. T. J. Johnson, N. Underwood y M. Vellend. 2008. Ecological consequences of genetic diversity. Ecology Letters 11(6): 609-623. DOI: https://doi. org/10.1111/j.1461-0248.2008.01179.x

Ibarra-Manríquez, G. y G. Cornejo-Tenorio. 2010. Diversidad de frutos de los árboles del bosque tropical perennifolio de México. Acta Botanica Mexicana 90: 51-104. DOI: https:// doi.org/10.21829/abm90.2010.299

Kamm, U., F. Gugerli, P. Rotach, P. Edwards y R. Holderegger. 2010. Open areas in a landscape enhance pollen-mediated gene flow of a tree species: evidence from northern Switzerland. Landscape Ecology 25(6): 903-911. DOI: https:// doi.org/10.1007/s10980-010-9468-z

Laborde, J. e I. Corrales-Ferrayola. 2012. Direct seeding of Brosimum alicastrum Sw. (Moraceae) and Enterolobium cyclocarpum (Jacq.) Griseb. (Mimosaceae) in different habitats in the dry tropics of central Veracruz. Acta Botanica Mexicana 100: 107-134. DOI: https://doi.org/10.21829/ abm100.2012.33

Lasso, E., J. W. Dalling y E. Bermingham. 2011. Strong spatial genetic structure in five tropical Piper species: should the Baker-Federov hypothesis be revived for tropical shrubs? Ecology and Evolution 1(4): 502-516. DOI: https://doi. org/10.1002/ece3.40

Lobova, T. A., S. A. Mori, F. Blanchard, H. Peckham y P. Charles-Dominique. 2003. Cecropia as a food resource for bats in French Guiana and the significance of fruit structure in seed dispersal and longevity. American Journal of Botany 90(3): 38-403. DOI: https://doi.org/10.3732/ajb.90.3.388

Loveless, M. D. y J. L. Hamrick. 1984. Ecological determinants of genetic structure in plant populations. Annual Review of Ecology and Systematics 15: 65-95. DOI: https://doi. org/10.1146/annurev.es.15.110184.000433

Lozano, U. F., V. W. Herrera y G. Viera. 2011. Desarrollo inicial de Aniba rosaeodora Ducke en claros artificiales de bosque pri- 
mario, Amazonia Central brasilera. Ingenierias y Amazonia 4(1): 5-18.

Maldonado Méndez, M. L., D. A. Rodríguez Trejo, E. Guízar Nolazco, J. Velázquez Martínez y S. Náñez Jiménez. 2009. Reducción en riqueza de especies arbóreas por incendios en la Reserva Selva El Ocote, Chiapas. Revista de Ciencia Forestal en México 34(106): 127-148.

Manzanilla-Quiñones U., y O. A. Aguirre-Calderón. 2017. Zonificación climática actual y escenarios de cambio climático para la Reserva de la Biosfera Selva El Ocote en Chiapas, México. In: Ruiz-Montoya, L., G. Álvarez-Gordillo, N. Ramírez-Marcial y B. Cruz-Salazar (eds.). Vulnerabilidad social y biológica ante el cambio climático en la Reserva de la Biosfera Selva El Ocote. El Colegio de la Frontera Sur. San Cristóbal de Las Casas, Chiapas, México. Pp. 25-66.

Martínez-Orea, Y., A. S. Castillo y C. P. Guadarrama. 2009. La dispersión de frutos y semillas y la dinámica de comunidades. Ciencias 96: 38-41.

McCarthy, C. 1998. Chromas v. 1.45. School of Health Science, Griffith University Queensland. Queensland, Australia.

Mendoza-Arroyo, G. E., A. Morón-Ríos, M. González-Espinosa, J. A. Alayón-Gamboa y P. A. Macario-Mendoza. 2020. La superviviencia y desarrollo de plántulas de Brosimum alicastrum (Moraceae) y Psidum sartorianum (Myrtaceae) difieren en condiciones de inundación. Acta Botanica Mexicana 127: e1548. DOI: https://doi.org/10.21829/ abm127.2020.1548

Muller-Landau, H. C. y B. D. Hardesty. 2005. Seed dispersal of woody plants in tropical forests: concepts, examples and future directions. In: Burslem, D., M. A. Pinard y S. D. Hartley (ed.). Biotic interactions in the tropics: Their role in the maintenance of species diversity. Cambridge University Press. Edinburg, UK. Pp. 268-300. DOI: https://doi. org/10.1017/cbo9780511541971.012

Muñoz-Alonso, L. A., J. Nieblas-Camacho, M. A. Chau-Cortez, A. B. González-Navarro, J. López-Pérez y J. Pérez-López. 2017. Diversidad de anfibios y reptiles en la Reserva de la Biosfera Selva El Ocote: su vulnerabilidad ante la fragmentación y el cambio climático. In: Ruiz-Montoya, L., G. Álvarez-Gordillo, N. Ramírez-Marcial y B. Cruz-Salazar (eds.). Vulnerabilidad social y biológica ante el cambio climático en la Reserva de la Biosfera Selva El Ocote. El Colegio de la Frontera Sur. San Cristóbal de Las Casas, Chiapas, México. Pp. 395-488.
Nason, J. D. 2002. La estructura genética de las poblaciones de árboles. In: Guariguatta, M. R., G. H. Kattan (eds.). Ecología y conservación de bosques neotropicales. LUR Ediciones. Cartago, Costa Rica. Pp. 299-328.

Nassar, J. M., A. E García y J. A. González. 2011. Patrones de diversidad genética en especies arbóreas de bosques secos fragmentados en Venezuela. Interciencia 36(12): 914-922.

Nathan, R. y H. C. Muller-Landau. 2000. Spatial patterns of seed dispersal, their determinants and consequences for recruitment. Trends in Ecology and Evolution 15(7): 278-285. DOI: https://doi.org/10.1016/s0169-5347(00)01874-7

Nei, M. 1987. Molecular Evolutionary Genetics. Columbia University Press, New York, USA. 512 pp.

Ornelas, J. F., E. Gándara, A. A. Vásquez-Aguilar, S. RamírezBarahona, A. E. Ortiz-Rodriguez, C. González, M. T. Mejía Saules y E. Ruiz-Sanchez. 2016. A mistletoe tale: postglacial invasion of Psittacanthus schiedeanus (Loranthaceae) to Mesoamerican cloud forests revealed by molecular data and species distribution modeling. BMC Evolutionary Biology 16: 78. DOI: https://doi.org/10.1186/s12862-0160648-6

Pennington, T. y J. Sarukhán. 2005. Árboles tropicales de México: manual para la identificación de las principales especies. Segunda edición. Fondo de Cultura Económica. Cd. Mx., México. 523 pp.

Piñero, D., J. Caballero, D. Cabrera, C. E. Canteros, A. Casas, A. Castañeda, A. Castillo, R. Cerritos, O. Chassin-Noria, P. Colunga-GarcíaMarin, P. Delgado. P. Díaz-Jaimes. L. E. Eguiarte, A. E. Escalante, B. Espinoza, A. Fleury, S. Flores Ramírez, G. Fragoso, J. González-Astorga, V. I. Villanueva, E. Martínez, F. Martinez, J. Martínez-Castillo, A. Mastretta Yanes, R. Medellín, L. Medrano-González, F. Molina-Freaner, B. Morales Vela, A. Murguía Vega, E. P. de la Cruz, M. R. Reyes-Montes, M. R. Robles Saavedra, G. Rodríguez-Arellanes, L. Rojas Bracho, R. Romero-Martínez, Jorge H. SahazaCardona, R. Salas Lizana, E. Sciutto, C. S. Baker, Y. Schramm Urrutia, C. Silva, V. Souza, M. L. Taylor, J. Urbán Ramírez, Manuel Uribe-Alcocer, M. J. Vázquez Cuevas, E. VázquezDomínguez, A. P. Vovides, A. Wegier, A. Zaldívar Riverón y G. Zúiga. 2008. La diversidad genética como instrumento para la conservación y el aprovechamiento de la biodiversidad: estudios en especies mexicanas. In: Piñero, D. (ed.). Capital Natural de México, volumen I: Conocimiento actual 
de la biodiversidad. Comisión Nacional para el Conocimiento y Uso de la Biodiversidad. Cd. Mx., México. Pp. 437-483.

Plomion, C., G. Leprovost y A. Stokes. 2001. Wood formation in trees. Plant Physiology 127(4): 1513-1523. DOI: https:// doi.org/10.1104/pp.010816

Polzin, T. y S. V. Daneshmand. 2003. On Steiner trees and minimum spanning trees in hypergraphs. Operations Research Letters 31(1): 12-20. DOI: https://doi.org/10.1016/S01676377(02)00185-2

Qin, Y., M. Li, Y. Cao, Y. Gao y W. Zhang. 2017. Molecular thresholds of ITS2 and their implications for molecular evolution and species identification in seed plants. Scientific Reports 7(1): 17316. DOI: https://doi.org/10.1038/s41598-017-17695-2

Quezada Moreno, W. F., W. D. Quezada Torres e I. Gallardo Aguilar. 2016. Plantas mucilaginosas en la clarificación del jugo de la caña de azúcar. Centro Azúcar 43(2): 1-11.

Ramírez-Marcial, N., M. Martínez-Icó, A. Luna-Gómez, C. Buet y N. E. Taylor-Aquino. 2017. Diversidad local y regional de árboles en la Reserva de la Biosfera Selva El Ocote, Chiapas. In: Ruiz-Montoya, L., G. Álvarez-Gordillo, N. Ramírez-Marcial y B. Cruz-Salazar (eds.). Vulnerabilidad social y biológica ante el cambio climático en la Reserva de la Biosfera Selva El Ocote. El Colegio de la Frontera Sur. San Cristóbal de Las Casas, Chiapas, México. Pp. 255-308.

Ricker, M., I. Ramírez-Krauss, G. Ibarra-Manríquez, E. Martínez, C. H. Ramos, G. González-Medellín, G. Gómez-Rodríguez, J. L. Palacio-Prieto y H. M. Hernández. 2007. Optimizing conservation of forest diversity: a country-wide approach in Mexico. Biodiversity and Conservation 16(6): 1927-1957. DOI: https://doi.org/10.1007/s10531-006-9112-z

Rodríguez-Correa, H., A. González-Rodríguez y K. Oyama. 2017. Perspectivas de la ecología molecular en un país megadiverso. Revista Mexicana de Biodiversidad 88: 3-13. DOI: https://doi.org/10.1016/j.rmb.2017.10.002

Rosas-Guerrero, V., R. Aguilar, S. Martén-Rodríguez, L. Ashworth, M. Lopezaraiza-Mikel, J. M. Bastida y M. Quesada. 2014. A quantitative review of pollination syndromes: do floral traits predict effective pollinators? Ecology Letters 17(3): 388-400. DOI: https://doi.org/10.1111/ele.12224

Rozas, J., J. Sánchez-DelBarrio, X. Messeguer y R. Rozas. 2003. DnaSP, DNA polymorphism analyses by the coalescent and other methods. Bioinformatics 19(18): 2496-2497. DOI: https://doi.org/10.1093/bioinformatics/btg359
Rzedowski, J. 2006. Vegetación de México. 1ra. Edición digital. Comisión Nacional para el Conocimiento y Uso de la Biodiversidad. Cd. Mx., México. https://www.biodiversidad. gob.mx/publicaciones/librosDig/pdf/VegetacionMx_Cont. pdf (consultado mayo de 2021).

SEMARNAT. 2001. Programa de manejo de la Reserva de la Biosfera Selva El Ocote, México. Secretaría de Medio Ambiente y Recursos Naturales. Ocozocoautla de Espinosa, Chiapas, México. 144 pp. http://centro.paot.org.mx/documentos/ ine/prog_manejo_selva_ocote.pdf (consultado mayo de 2021).

SEMARNAT. 2010. NORMA Oficial Mexicana NOM-059-SEMARNAT-2010, Protección ambiental-Especies nativas de México de flora y fauna silvestres-Categorías de riesgo y especificaciones para su inclusión, exclusión o cambio-Lista de especies en riesgo. Secretaría del Medio Ambiente y Recursos Naturales. Diario Oficial de la Federación. Cd. Mx., México. http://dof.gob.mx/nota_detalle.php?codigo=5173 091\&fecha=30/12/2010 (consultado mayo de 2021).

Tajima, F. 1989. Statistical method for testing the neutral mutation hypothesis by DNA polymorphism. Genetics 123(3): 585-595. DOI: https://doi.org/10.1093/genetics/123.3.585

Thompson, J., T. Gibson, F. Plewniak, F. Jeanmougin y D. Higgins. 1997. The CLUSTAL_X Windows interface: flexible strategies for multiple sequence alignment aided by quality analysis tools. Nucleic Acids Research 25(24): 4876-4882. DOI: https://doi.org/10.1093/nar/25.24.4876

Turner, I. M. 2004. The ecology of trees in the tropical rain forest. Cambridge University Press. Cambridge, UK. 298 pp. DOI: https://doi.org/10.1017/CB09780511542206

Vellend, M. 2005. Species diversity and genetic diversity: parallel processes and correlated patterns. The American Naturalist 166(2):199-215. DOI: https://doi.org/10.1086/431318

Vera-Maloof, F. Z., L. Ruiz-Montoya. y N. Ramírez Marcial. 2019. Does the genetic diversity of Macuilillo, Oreopanax xalapensis (Araliaceae), change along successional gradients of the Montane Cloud Forest? Tropical Conservation Science 12: 1-11. DOI: https://doi.org/10.1177/1940082919872923

Vibrans, H. 2009. Malezas de México. Comisión Nacional de Uso y Conocimiento de la Biodiversidad, Ciudad de México, México. http://www.conabio.gob.mx/malezasdemexico/tiliaceae/heliocarpus-appendiculatus/fichas/ficha.htm\#9.\%20 Referencias (consultado mayo de 2021). 
White, T. J., T. Bruns, S. Lee y J. Taylor. 1990. A Guide to Methods and Applications: Amplification and direct sequencing of fungal ribosomal RNA genes for phylogenetics. In: Innis, M. A., D. H. Gelfand, J. J. Sninsky y T. H. White (eds.). PCR protocols: a guide to methods and applications. Academic Press. New York, USA. Pp. 315-322. 
Apéndice: Número de acceso en GenBank (NAGB; GenBank, 2021) de muestras de cuatro especies de árboles tropicales en tres localidades de la Reserva de la Biosfera Selva El Ocote, Chiapas, México. Se registraron secuencias únicas para ITS-1 e ITS-2 de Brosimum alicastrum Sw. (16 secuencias) Sapium macrocarpum Müll. Arg. (24), Cecropia peltata L. (12) y Heliocarpus appendiculatus Turcz. (10).

\begin{tabular}{|c|c|c|c|}
\hline Familia & Especie & Comunidad & NAGB \\
\hline \multirow[t]{16}{*}{ Moraceae } & Brosimum alicastrum Sw. & Emilio Rabasa & MW494456 \\
\hline & Brosimum alicastrum Sw. & Emilio Rabasa & MW494457 \\
\hline & Brosimum alicastrum Sw. & Emilio Rabasa & MW494458 \\
\hline & Brosimum alicastrum Sw. & Emilio Rabasa & MW494459 \\
\hline & Brosimum alicastrum Sw. & Emilio Rabasa & MW494460 \\
\hline & Brosimum alicastrum Sw. & Emilio Rabasa & MW494461 \\
\hline & Brosimum alicastrum Sw. & Emilio Rabasa & MW494462 \\
\hline & Brosimum alicastrum Sw. & Emilio Rabasa & MW494463 \\
\hline & Brosimum alicastrum Sw. & Emilio Rabasa & MW494464 \\
\hline & Brosimum alicastrum Sw. & Emilio Rabasa & MW494465 \\
\hline & Brosimum alicastrum Sw. & Emilio Rabasa & MW494466 \\
\hline & Brosimum alicastrum Sw. & Emilio Rabasa & MW494467 \\
\hline & Brosimum alicastrum Sw. & Emilio Rabasa & MW494468 \\
\hline & Brosimum alicastrum Sw. & Emilio Rabasa & MW494469 \\
\hline & Brosimum alicastrum Sw. & Emilio Rabasa & MW494470 \\
\hline & Brosimum alicastrum Sw. & Emilio Rabasa & MW494471 \\
\hline \multirow[t]{12}{*}{ Cecropiaceae } & Cecropia peltata $\mathrm{L}$. & Emilio Rabasa & MW494472 \\
\hline & Cecropia peltata L. & Emilio Rabasa & MW494474 \\
\hline & Cecropia peltata L. & Emilio Rabasa & MW494477 \\
\hline & Cecropia peltata $\mathrm{L}$. & Emilio Rabasa & MW494478 \\
\hline & Cecropia peltata L. & Emilio Rabasa & MW494480 \\
\hline & Cecropia peltata L. & Emilio Rabasa & MW494483 \\
\hline & Cecropia peltata L. & Nuevo San Juan Chamula & MW494475 \\
\hline & Cecropia peltata $\mathrm{L}$. & Nuevo San Juan Chamula & MW494476 \\
\hline & Cecropia peltata L. & Nuevo San Juan Chamula & MW494481 \\
\hline & Cecropia peltata $\mathrm{L}$. & Nuevo San Juan Chamula & MW494482 \\
\hline & Cecropia peltata L. & Veinte Casas & MW494473 \\
\hline & Cecropia peltata $\mathrm{L}$. & Veinte Casas & MW494479 \\
\hline \multirow[t]{10}{*}{ Malvaceae } & Heliocarpus appendiculatus Turcz. & Emilio Rabasa & MW494486 \\
\hline & Heliocarpus appendiculatus Turcz. & Emilio Rabasa & MW494491 \\
\hline & Heliocarpus appendiculatus Turcz. & Nuevo San Juan Chamula & MW494484 \\
\hline & Heliocarpus appendiculatus Turcz. & Nuevo San Juan Chamula & MW494488 \\
\hline & Heliocarpus appendiculatus Turcz. & Nuevo San Juan Chamula & MW494489 \\
\hline & Heliocarpus appendiculatus Turcz. & Nuevo San Juan Chamula & MW494493 \\
\hline & Heliocarpus appendiculatus Turcz. & Veinte Casas & MW494485 \\
\hline & Heliocarpus appendiculatus Turcz. & Veinte Casas & MW494487 \\
\hline & Heliocarpus appendiculatus Turcz. & Veinte Casas & MW494490 \\
\hline & Heliocarpus appendiculatus Turcz. & Veinte Casas & MW494492 \\
\hline \multirow[t]{2}{*}{ Euphorbiaceae } & Sapium macrocarpum Müll. Arg. & Emilio Rabasa & MW494498 \\
\hline & Sapium macrocarpum Müll. Arg. & Emilio Rabasa & MW494499 \\
\hline
\end{tabular}


Apéndice: Continuación.

\begin{tabular}{|c|c|c|c|}
\hline Familia & Especie & Comunidad & NAGB \\
\hline \multirow[t]{22}{*}{ Euphorbiaceae } & Sapium macrocarpum Müll. Arg. & Emilio Rabasa & MW494500 \\
\hline & Sapium macrocarpum Müll. Arg. & Emilio Rabasa & MW494505 \\
\hline & Sapium macrocarpum Müll. Arg. & Emilio Rabasa & MW494510 \\
\hline & Sapium macrocarpum Müll. Arg. & Emilio Rabasa & MW494511 \\
\hline & Sapium macrocarpum Müll. Arg. & Emilio Rabasa & MW494512 \\
\hline & Sapium macrocarpum Müll. Arg. & Emilio Rabasa & MW494517 \\
\hline & Sapium macrocarpum Müll. Arg. & Nuevo San Juan Chamula & MW494496 \\
\hline & Sapium macrocarpum Müll. Arg. & Nuevo San Juan Chamula & MW494504 \\
\hline & Sapium macrocarpum Müll. Arg. & Nuevo San Juan Chamula & MW494508 \\
\hline & Sapium macrocarpum Müll. Arg. & Nuevo San Juan Chamula & MW494516 \\
\hline & Sapium macrocarpum Müll. Arg. & Veinte Casas & MW494494 \\
\hline & Sapium macrocarpum Müll. Arg. & Veinte Casas & MW494495 \\
\hline & Sapium macrocarpum Müll. Arg. & Veinte Casas & MW494497 \\
\hline & Sapium macrocarpum Müll. Arg. & Veinte Casas & MW494501 \\
\hline & Sapium macrocarpum Müll. Arg. & Veinte Casas & MW494502 \\
\hline & Sapium macrocarpum Müll. Arg. & Veinte Casas & MW494503 \\
\hline & Sapium macrocarpum Müll. Arg. & Veinte Casas & MW494506 \\
\hline & Sapium macrocarpum Müll. Arg. & Veinte Casas & MW494507 \\
\hline & Sapium macrocarpum Müll-Arg. & Veinte Casas & MW494509 \\
\hline & Sapium macrocarpum Müll. Arg. & Veinte Casas & MW494513 \\
\hline & Sapium macrocarpum Müll. Arg. & Veinte Casas & MW494514 \\
\hline & Sapium macrocarpum Müll. Arg. & Veinte Casas & MW494515 \\
\hline
\end{tabular}

